\title{
Stability Analysis of Soybean (Glycine Max L. Merrill) Genotypes
}

\section{Across North West of Ethiopia}

\author{
Tadesse Ghiday
}

Holetta Agricultural Research Center, Ethiopia

\begin{abstract}
Yield stability is an interesting feature of today's soybean breeding programs, due to the high annual variation in mean yield, particularly in the areas across North West of Ethiopia. Nineteen soybean (Glycine max. L Merrill) genotypes sourced from Pawe Agricultural Research Center were tested for yield stability and performance in four environments between 2014 and 2016 using various stability statistics. The experiment of each environment was laid out in a randomized complete block design with four replications. Combined analysis of variance of grain yield showed highly significant differences among genotypes and environments. Significant GEI indicated differential performance of genotypes across environments. Considering coefficient of several linear regression models, including conventional, adjusted independent and Tai models as well as deviation variance from these models, genotype G18 was the most stable genotype. Stability analysis in basis of parameters like environmental variance, coefficient of variation, stability variance, genotypic stability and Superiority index, genotypes G10 and G18 were the most stable genotypes. The result of principal component analysis of stability statistics and mean yield indicated that slope of linear regression of both conventional and independent models were useful for simultaneously selecting for high yield and stability. The plot of the first two principal components also showed that the stability statistics could be grouped as two distinct classes that corresponded to different static and dynamic concepts of stability. Finally, regarding both mean yield and most of stability characteristics, genotypes $G 10$ and G18 were found to be the most stable genotypes. Such an outcome could be employed in the future to delineate rigorous recommendation strategies as well as to help define stability concepts for other crops.
\end{abstract}

Keywords: Adaptation, Linear regression model, Multi-environment trials, Principal component analysis

\section{INTRODUCTION}

Soybean, being a source of protein and oil, is an important crop in Ethiopia. However, its production fluctuates mainly because of the use of environment-sensitive genotypes and fluctuating environmental conditions. High grain yield has been the main aim in soybean improvement and the soybean breeders are concentrating to improve the yield potential of soybean by developing new genotypes [1]. A crop genotype is considered to be the most favorable one if it has a high mean yield and a consistent performance when grow across diverse locations and years [2]. Plant breeders usually evaluate a series of genotypes across environments before a new improved genotype is released for production to farmers [3]. Therefore, indication of genotype(s) that perform consistently across environments should be emphasized [4]. In most of the genotype evaluation trials, genotype $x$ environment (GE) interaction is observed as a common phenomenon [5]. The GE interaction complicates selection of truly superior genotypes in breeding and performance testing programs.

Several statistical procedures can be used for measuring crop yield stability. These statistical methods can be divided into two major groups, univariate and multivariate stability parameters [6]. Among univariate procedures, the most popular and most widely used is the joint linear regression analysis as proposed by several [7], [8], [9] and [10]. The nature of yield stability in terms of statistical parameters should follow the confirmatory analysis of GE interaction. It has been demonstrated that relatively a linear relationship exists between phenotype and environment when the environment is measured by its effect on the genotype yield performance. Although there are some statistical and biological limitations in the linear regression model (Crossa [11] and Flores [12]), it provides useful information when numbers of studied genotypes and test environments are relatively large.

The joint linear regression procedure provides conceptual model for genotypic stability and is simple in calculation and application [13].This modeling provides two parameters of stability including the 
regression coefficient (linear sensitivity) and the deviation from linearity (non linear sensitivity (which use as the basis for understanding of the nature of GE interaction in multi-environment trial [14]. Also, the ability of the linear regression model for description of the observed variation could be determined using the coefficient of determination (R2) Pinthus [15], which is computed by individual linear regression analysis. Therefore, the linear regression model provides useful estimates for yield stability parameters when there are no extreme environments that bias regression slopes [16]. Another stability measures is the genotypic stability which is established on regression analysis since it uses the minimum slope from the conventional regression model.

Since Zobel [17] yield stability was measured by the amount of the variance of a genotype across test environments. Wricke [18] proposed the use of ecovalence, the contribution of genotype a genotype to the GE interaction as a criterion of yield stability. Also, yield stability can be measured across all interaction effects, as devised by Shukla's [19] stability of variance (SV) and the environmental variances. Lin and Binns [20] defined the superiority Index (PI) as the genotype general superiority and defined it as the distance mean square between the genotype's response and the maximum response over locations. Some plant breeders indicated that the above mentioned stability parameters follow a static concept of stability. Peterson [21] reported that the concept of optimal genotype differ somewhat from the conventionally used to describe yield stability. For breeders, stability is important in terms of changing ranks of genotypes across test environments and influences selection efficiency during improvement programs. For farmers, high yielding characteristics of genotypes is very important, regardless of changing genotypes' ranks. However, the genotypes yield usually reacts to favorable or unfavorable environmental conditions. A genotype is therefore considered to be stable if its contribution to the GE interaction is low. The objective of this study was to determine the stability of grain yield in different soybean genotypes with various univariate parametric stability models and to identify soybean genotypes that have both high mean yield and stable yield performance for North West Ethiopian areas.

\section{MAterial AND Methods}

\section{Planting Materials and Testing Locations}

Nineteen soybean genotypes were tested in years (2012-2013, 2013-2014 and 2015-2016) at four different locations Asossa, Dibate, Mankush and Pawe. The locations are representatives of the low land of the country were soybean is widely cultivated as major rotation crop with cereals. Each year at each location was considered as a separate environment, making four test environments for the study. The descriptions of the four test locations and the nineteen test cultivars are given in table 1 and 2, respectively.

Table 1. Description of the test environments

\begin{tabular}{|l|l|l|l|l|l|}
\hline \multirow{2}{*}{ Environment } & \multicolumn{5}{|l|}{ Geographical Position } \\
\cline { 2 - 6 } & Longitude & Latitude & Altitude m) & Soil Texture & Rainfall (mm) \\
\hline Pawe & $36^{\circ} 03 \mathrm{E}$ & $11^{\circ} 09^{\prime} \mathrm{N}$ & 1050 & Silt clay Loam & $1000-1500$ \\
\hline Asossa & $37^{0} 04^{\prime} \mathrm{E}$ & $12^{0} 60^{\prime} \mathrm{N}$ & 1155 & Silt clay Loam & $1200-1500$ \\
\hline Dibate & $36^{\circ} 26^{\prime} \mathrm{E}$ & $10^{\circ} 77^{\prime} \mathrm{N}$ & 1000 & Silt-Loam & $900-1400$ \\
\hline Mankush & $35^{\circ} 29^{\prime} \mathrm{E}$ & $10^{\circ} 272^{\prime} \mathrm{N}$ & 860 & Sandy-Loam & $500-1000$ \\
\hline
\end{tabular}

Table 2. Description of the 19 soybean genotypes used in the experiment.

\begin{tabular}{|l|l|l|l|l|l|l|l|l|}
\hline No & Genotype & Source & Year & No & Genotype & Source & Year \\
\hline G1 & Clark 63k & USA & 2005 & G11 & $\begin{array}{l}\text { Belessa-95 } \\
149)\end{array}$ & IITA/Nigeria & 2005 \\
\hline G2 & williams & USA & 2007 & G12 & Wello & IITA/Nigeria & 2005 \\
\hline G3 & Gizo & IITA/Nigeria & 2005 & G13 & Gozilla & IITA/Nigeria & 2007 \\
\hline G4 & Nyala & TURKEY & 2005 & G14 & Wogayen & IITA/Nigeria & 2005 \\
\hline G5 & AGS-7-1 & USA & 2005 & G15 & Davis & USA & 2005 \\
\hline G6 & $\begin{array}{l}\text { Afgat (TGX-1892- } \\
\text { 10F) }\end{array}$ & IITA/Nigeria & 2007 & G16 & Ethio-yugoslavia & USA & 2005 \\
\hline G7 & crowford & IITA/Nigeria & 2007 & G17 & Boshe & IITA/Nigeria & 2007 \\
\hline G8 & Cocker-240 & IITA/Nigeria & 2007 & G18 & Gishama & IITA/Nigeria & 2005 \\
\hline G9 & Jalele & IITA/Nigeria & 2007 & G19 & Nova & USA & 2005 \\
\hline G10 & Awassa-95 (G2261) & USA & 2005 & & & & \\
\hline
\end{tabular}


Source: Pawe Agricultural Research Center 2011

\section{Experimental Layout and Design}

The treatments were laid out in randomized complete block design with four replications. Each plot was four rows and $5 \mathrm{~m}$ long with spacing of $40 \mathrm{~cm}$ between rows. Fertilizer was applied to each plot at the rate of $100 \mathrm{~kg}$ diammonium phosphate at planting. Other agronomic practices were kept as none experimental variables and applied uniformly to the entire experimental area. For data analysis, grain yield measured from net plot of $4 \mathrm{~m}^{2}$ was converted into $\mathrm{kg} / \mathrm{ha}$ at $10 \%$ standard grain moisture content.

\section{Data Analysis}

The statistics used to assess the stability and adaptability of genotypic mean yield was genotype mean square across test environments or environmental variance (EV). Coefficient of variation (CV) for each genotype as used by Francis and Kannenberg [22], the genotypic ecovalence as proposed by Wricke [18], the GEI variance or stability variance as suggested by Shukla [19]), Genotypic stability (GS) of Hanson [23], Superiority Index (PI) measure and its mean squares of GE (MSGE) as used by Lin and Binns [20], Conventional linear regression coefficient as suggested by Finlay and Wilkinson [7], deviation from conventional regression mean square [8], Coefficient of determination for conventional linear regression model [15], Adjusted linear regression coefficient and deviation as proposed by Perkins and Jink [9], independent linear regression coefficient and deviation suggested by Freeman and Perkins [10], and the regression model of Tai [24] which uses alpha and lambda measures. A comprehensive SAS based program has become available, which calculates the most parametric stability statistics [27] which is used to calculate stability statistics.

\section{RESUlT}

Combined analysis of variance was performed to determine the effects of environment, genotype and GEI on grain yield of soybean genotypes regarding to result of Bartlett's homogeneity test. The main effects of genotype and environments were highly significant $(\mathrm{p}<0.01)$, and the GEI was also highly significant $(\mathrm{p}>0.01)$ (Table 3).

Table 3. ANOVA of 19 soybean genotypes grown in 4 different environments

\begin{tabular}{|l|l|l|l|l|}
\hline Source of variation & Degree of freedom & Sum of square & Mean Squares & \% of G+E+GE \\
\hline Environment (E) & 3 & 3777614488.6 & $1259204830^{* *}$ & 88.71725 \\
\hline Replication/E & 12 & 15259028.4 & $1271585.7^{\mathrm{ns}}$ & \\
\hline Genotype $(\mathrm{G})$ & 18 & 12809695.9 & $711649.77^{* *}$ & 3.008356 \\
\hline GE & 54 & 35232713.4 & $652457.66^{* *}$ & 8.274399 \\
\hline Error & 824 & 28161700 & 34176.82 & \\
\hline$* * *$ and ns, significant at $0.01,0.05$ probability level and non-significant respectively \\
\hline
\end{tabular}

The high significance of GEIs for grain yield of 19 soybean genotypes tested across four locations during three years is indicating the studied genotypes exhibited both crossover and non-crossover types of genotype by environment interactions. Complexity of grain yield as a quantitative trait is a result of diverse processes that occur during development. The larger degrees of genotype by environment interaction cause to the more dissimilar the genetic system controlling the physiological processes confirming adaptation to the different environments. The relative contribution of genotype by environment interaction effects for grain yield found in this study are similar to those found in other crop adaptation studies in rain fed environments [28][32]. Therefore, genotype by environment interaction that makes it difficult to select the best performing and most stable genotypes is an important consideration in plant breeding programs [29].

According to environmental variance [20] and coefficient of variation (CV) which represent Type I stability concept (Table 4), Genotypes G10 and G18 were the most stable genotypes (Table 4). Both of these stable genotypes had low mean yield and so static concept of stability. Traditionally, the term stability is used to characterize a genotype which indicates a relatively constant yield performance, independent environmental variations. This concept may be considered as static concept of stability [2]. In contrast, a genotype showing a constant yield in all environments does not necessarily respond to improved growing conditions and usually the most stable genotypes based on this idea had low mean yield. Genotypes G10, G18 and G19 were the most stable genotypes based on the ecovalance [18], genotypic stability [28] and the stability variance [19] which genotype G19 had relatively high 
mean yield (Table 4). The stability concept nature of W and GS stability statistics were as the same of static concept of stability.

Table 4. Stability parameters based on various univariate parametric methods, for the 19 soybean genotypes grown in 4 environments.

\begin{tabular}{|l|l|l|l|l|l|l|l|l|}
\hline Gen & MY & EV & CV & W & SV & GS & PI & MSGE \\
\hline G1 & 2497 & 1800695.7 & 55.3 & 1058772.6 & 81340.2 & 1486789.8 & 2427.5 & 39150.6 \\
\hline G2 & 2547.667 & 1674975.3 & 58.2 & 554764.3 & 41339.5 & 850693.0 & 2225.3 & 125700.3 \\
\hline G3 & 2488.333 & 1682988.2 & 58.1 & 634434.1 & 47662.5 & 933781.5 & 2233.1 & 119654.4 \\
\hline G4 & 2443.5 & 1669050.7 & 56.0 & 1282838.5 & 99123.2 & 1493480.7 & 2307.9 & 109273.3 \\
\hline G5 & 2386.083 & 1800695.7 & 55.3 & 1058772.6 & 81340.2 & 1486789.8 & 2127.5 & 130150.6 \\
\hline G6 & 2699.583 & 1672646.9 & 59.7 & 728623.2 & 55137.8 & 1002841.0 & 2165.7 & 153316.4 \\
\hline G7 & 2562.167 & 1913555.4 & 61.9 & 1027633.9 & 78668.8 & 1625081.8 & 2234.6 & 139680.6 \\
\hline G8 & 2421.167 & 1587082.9 & 60.7 & 557241.0 & 41536.1 & 723511.1 & 2076.2 & 202405.9 \\
\hline G9 & 2492.75 & 1656013.8 & 58.0 & 683374.6 & 51546.7 & 937863.0 & 2220.0 & 120073.7 \\
\hline G10 & 1931.833 & 1433041.7 & 54.7 & 408176.3 & 29705.5 & 363337.0 & 2189.7 & 131723.4 \\
\hline G11 & 2879.5 & 163861.3 & 58.3 & 571353.6 & 42656.1 & 811633.3 & 2194.2 & 142557.8 \\
\hline G12 & 2237.583 & 1636226.9 & 57.9 & 497752.2 & 36814.7 & 742629.4 & 2210.4 & 119422.5 \\
\hline G13 & 2453.417 & 1657283.9 & 59.4 & 604922.0 & 45320.3 & 869530.2 & 2165.9 & 145299.5 \\
\hline G14 & 2302.25 & 1578199.9 & 58.7 & 270753.7 & 18799.0 & 454072.7 & 2138.7 & 169192.1 \\
\hline G15 & 2546.083 & 1435356.1 & 58.7 & 940914.1 & 71986.3 & 843459.7 & 2040.3 & 259388.6 \\
\hline G16 & 2199.083 & 2166899.5 & 64.1 & 1145708.6 & 88239.9 & 2103721.8 & 2297.0 & 86859.4 \\
\hline G17 & 2649.583 & 1727549.4 & 58.8 & 683055.6 & 51521.4 & 1042894.6 & 2234.9 & 103890.5 \\
\hline G18 & 1940.417 & 1326107.4 & 53.3 & 844553.7 & 64338.7 & 596392.7 & 2161.9 & 179135.6 \\
\hline G19 & 2020.833 & 1516007.3 & 54.8 & 382012.4 & 27629.0 & 462069.4 & 2248.1 & 111145.3 \\
\hline
\end{tabular}

Mean yield (MY), environmental variance (EV), Coefficient of variance (CV), Ecovalance (W), Stability variance (SV), genotypic stability (GS), Priority index (PI) and Mean squares of genotype by environment interaction (MSGE).

According to superiority index (PI) measure, genotypes G8, G14 and G15 were the most stable genotypes while based on mean squares of GE (MSGE) of PI, G1, G16 and G17 were the most stable genotypes (Table 4). Considering PI and MSGE simultaneously G10, G17 and G12 were the most stable genotypes. It is interesting that genotypes G17 had relatively high mean yield and so could be regarded as the most favorable genotype. The stability procedure of Lin and Binns [20] reflects type IV stability concept which is distinct from static or dynamic concept of stability [30]. The static type of stability is not acceptable to most plant breeders, who could prefer a dynamic concept of stability [2]. In this type of stability, it is not need that the genotypic response to environmental variations should be equal for all studied genotypes [12]. According to conventional linear regression coefficient [7], Genotypes G1, G7 and G16 were the most stable genotypes while based on deviation from conventional regression mean square [8], genotypes G10, G18 and G15 had the lowest amounts and where the most stable genotypes (Table 5). Also most of the studied genotypes had the high coefficient of determination for conventional linear regression model [15] and therefore the linear regression model could describe GEI as well as possible. Considering FW, ER, R2 and mean yield simultaneously genotypes G13 and G17 were the most favorable genotypes. According to adjusted linear regression coefficient [9], Genotypes G1, G7 and G16 were the most stable genotypes while based on deviation from this regression mean square, genotypes G10, G5 and G14 had the lowest amounts and were the most stable genotypes (Table 5). Considering adjusted linear regression parameters and mean yield simultaneously genotypes G7 and G16 were the most favorable genotypes.

According to slopes of independent linear regression coefficient [10], genotypes G6, G7 and G16 were the most stable genotypes while based on its deviation from regression mean square, genotypes G5, G8 and G15the lowest amounts and were the most stable genotypes (Table 5). Considering both regression coefficient and deviation mean square simultaneously, genotypes G7, G15 and G16 were the most stable genotypes. It is interesting genotypes G7 and G16 had relatively high mean yield and so it seems that this regression model could identified high mean yield performance genotypes as the most stable ones. According to Tai's [24] regression coefficient (Alpha), genotypes G7, G18 and G16 were the most stable genotypes while based on its deviation from regression mean square (Lambda), genotypes G10, G14 and G16 with the lowest amounts, were the most stable genotypes (Table 5). 
Simultaneous regarding Alpha and Lambda, genotypes G10, G18 and G16 were the most stable genotypes. Among these stable genotypes, only G16 had the high mean yield.

Table 5. Stability parameters based on various regression models, for the 19 soybean genotypes grown in 4 environments.

\begin{tabular}{|l|l|l|l|l|l|l|l|l|l|}
\hline Gen & FW & ER & R2 & PJ & RPD & FP & RFD & alpha & lambda \\
\hline G1 & 1.038 & 2797461.3 & 95.93 & 0.03811 & 114020.5 & 0.861 & 257846.1 & 0.0647 & 2.932 \\
\hline G2 & 1.010 & 2605261.9 & 97.64 & 0.01012 & 61385.1 & 0.848 & 187323.4 & 0.0172 & 1.610 \\
\hline G3 & 1.011 & 2617688.5 & 97.32 & 0.01085 & 70199.4 & 0.850 & 240295.2 & 0.0184 & 1.841 \\
\hline G4 & 0.992 & 25936143.5 & 94.52 & -0.00795 & 142380.0 & 0.774 & 298422.0 & -0.0135 & 3.741 \\
\hline G5 & 0.964 & 2355070.4 & 98.33 & -0.03562 & 39282.7 & 0.820 & 52944.3 & -0.0605 & 0.975 \\
\hline G6 & 1.006 & 2601819.3 & 96.89 & 0.00552 & 80882.1 & 0.895 & 256494.0 & 0.0094 & 2.126 \\
\hline G7 & 1.074 & 2962985.9 & 96.62 & 0.07401 & 100525.4 & 0.947 & 119388.4 & 0.1256 & 2.393 \\
\hline G8 & 0.983 & 2468045.1 & 97.52 & -0.01735 & 61165.0 & 0.816 & 91861.8 & -0.0295 & 1.595 \\
\hline G9 & 1.001 & 2576017.3 & 97.05 & 0.00134 & 75926.0 & 0.867 & 263532.9 & 0.0023 & 1.997 \\
\hline G10 & 0.938 & 2219566.7 & 98.40 & -0.06208 & 35743.4 & 0.825 & 125018.9 & -0.1054 & 0.764 \\
\hline G11 & 0.998 & 2548554.8 & 97.51 & -0.00167 & 63476.8 & 0.825 & 339878.0 & -0.0028 & 1.669 \\
\hline G12 & 0.999 & 2545240.6 & 97.83 & -0.00070 & 55304.6 & 0.827 & 266240.0 & -0.0012 & 1.454 \\
\hline G13 & 1.003 & 2577966.8 & 97.39 & 0.00348 & 67183.3 & 0.828 & 384825.0 & 0.0059 & 1.766 \\
\hline G14 0.986 & 2454506.5 & 98.79 & -0.01374 & 29613.1 & 0.768 & 178521.2 & -0.0233 & 0.770 \\
\hline G15 & 0.927 & 2219405.6 & 95.92 & -0.07323 & 91175.4 & 0.878 & 104156.6 & -0.1243 & 2.152 \\
\hline G16 & 1.150 & 3314330.2 & 97.90 & 0.15040 & 70898.3 & 1.041 & 122956.1 & 0.2553 & 0.830 \\
\hline G17 & 1.024 & 2685903.3 & 97.23 & 0.02366 & 74499.0 & 0.886 & 306111.5 & 0.0402 & 1.934 \\
\hline G18 & 0.895 & 2035260.3 & 96.76 & -0.10516 & 66265.8 & 0.711 & 208239.1 & -0.1785 & 1.237 \\
\hline G19 & 0.938 & 2697461.3 & 93.93 & 0.01811 & 304020.5 & 0.828 & 387846.1 & 0.0657 & 2.632 \\
\hline
\end{tabular}

Slope of conventional regression coefficient $(\mathrm{FW})$, Deviation from conventional regression (ER). Coefficient of determination (R2), Slope of adjusted regression model of Perkins and Jinks (PJ), Residual mean squares from the regression of Perkins and Jinks model (RPD), Slope of independent regression model of Freeman and Perkins (FP), Residual mean squares from the regression of Freeman and Perkins's model (RFD), $\alpha$ of tai procedure (1971) and $\lambda$ of Tai

\section{DisCUSSION}

In this study several regression models are used for interpreting GEI. For using regression slopes as stability parameters, regression model need that heterogeneity for genotype regressions account relatively a high portion of the GEI variations [25]. Also, the most favorable genotype is the one that combines both high mean yield and stability performance together and so it is acceptable over a wide range of environmental conditions [26]. This idea for identifying favorable genotypes reflects dynamic concept of stability. Adie [31] reported that the regression coefficients of the most of the regression models benefits from dynamic concepts of stability and could be useful for detecting the most stable genotypes. Anyhow, each statistic reflects different aspects of yield stability concepts and no single method can adequately explain genotype performance across different environments [12] [31]. Therefore it seems that the reliable decision about GEI and effective selection of favorable genotypes, it is better multi-environment trails dataset is evaluated through different aspects of stability concepts.

To better show associations among genotypes based on different stability statistics, the two-way dataset of genotypes was analyzed further using a clustering procedure. The Ward's hierarchical clustering procedure indicated that the nineteen soybean genotypes could be classified into three major groups (Table 6). Cluster I include genotypes G1, G9, G3, G2, G15, G7, G4, G13, G8, G5, G6, G17,G12, G16 and 14 which were moderate or low mean yielding genotypes and low or moderate stability characteristics. Cluster II include genotypes G10, G18 and G19 which have low mean yielding and high stability characteristics. Cluster III have solitary genotype G11 which have high mean yielding genotype and low stability characteristics. Regarding almost the most of the stability statistics results as well as mean yield, genotypes G10, G18 and G19 could be introduced as the most favorable genotypes. 
Table 6. Hierarchical cluster analysis of the 19 soybean genotypes based on Ward's method using GXE matrix of mean yield.

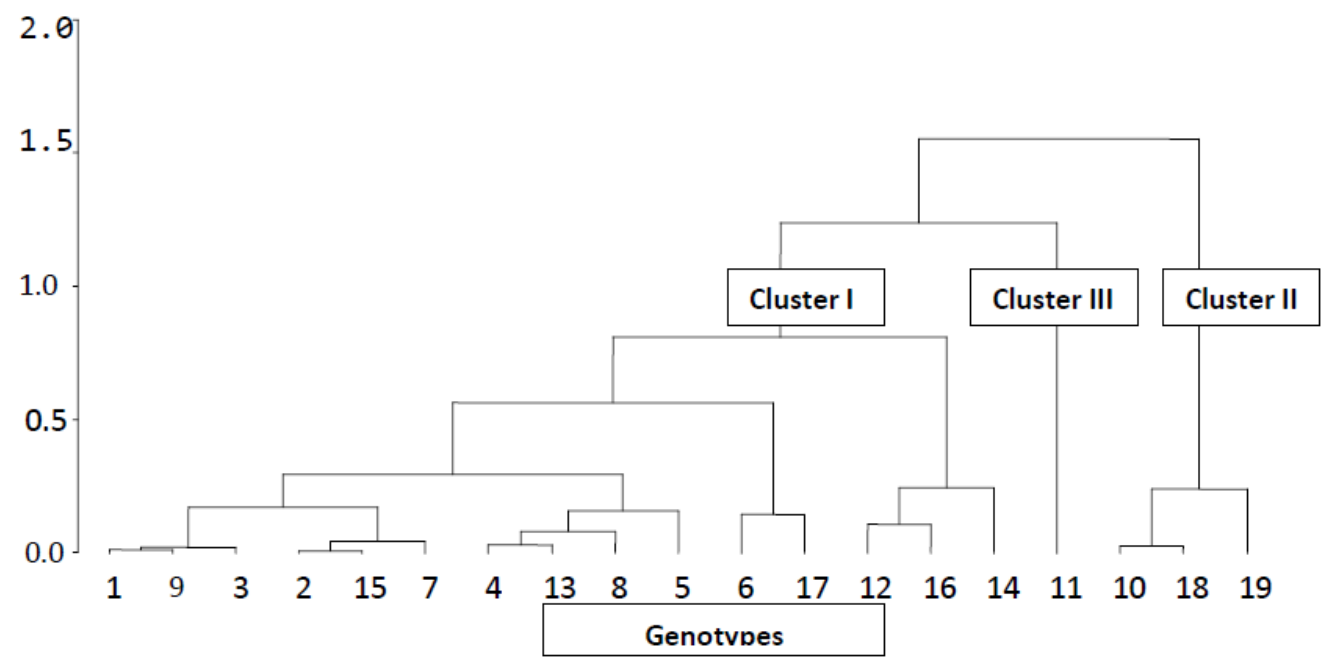

Yield stability should be considered as an important aspect of multi-environment trails and so plant breeders need some stability statistics which provide a reliable measure of yield stability. Anyhow for a successful breeding program or new genotypes evaluation trials, both stability and yield must be regarded simultaneously. Kang and Pham (1991) discussed several methods of simultaneous selection for yield and stability and relationships among them. This consideration may be reflects static or dynamic nature of different stability statistics. Also it is possible the crop nature or genetically differences among studied genotypes cause to various conclusions. However, our clustering results indicated there are three distinct groups based on stability performance and mean yield properties. Adie [13] evaluated the usefulness of several stability statistics for simultaneously selecting for high yield and stability of performance and reported relatively similar results.

Table 7. PCA plot of ranks of stability of yield, estimated by different methods using yield data from 19 soybean genotypes grown in four environments and showing interrelationships among these parameters.

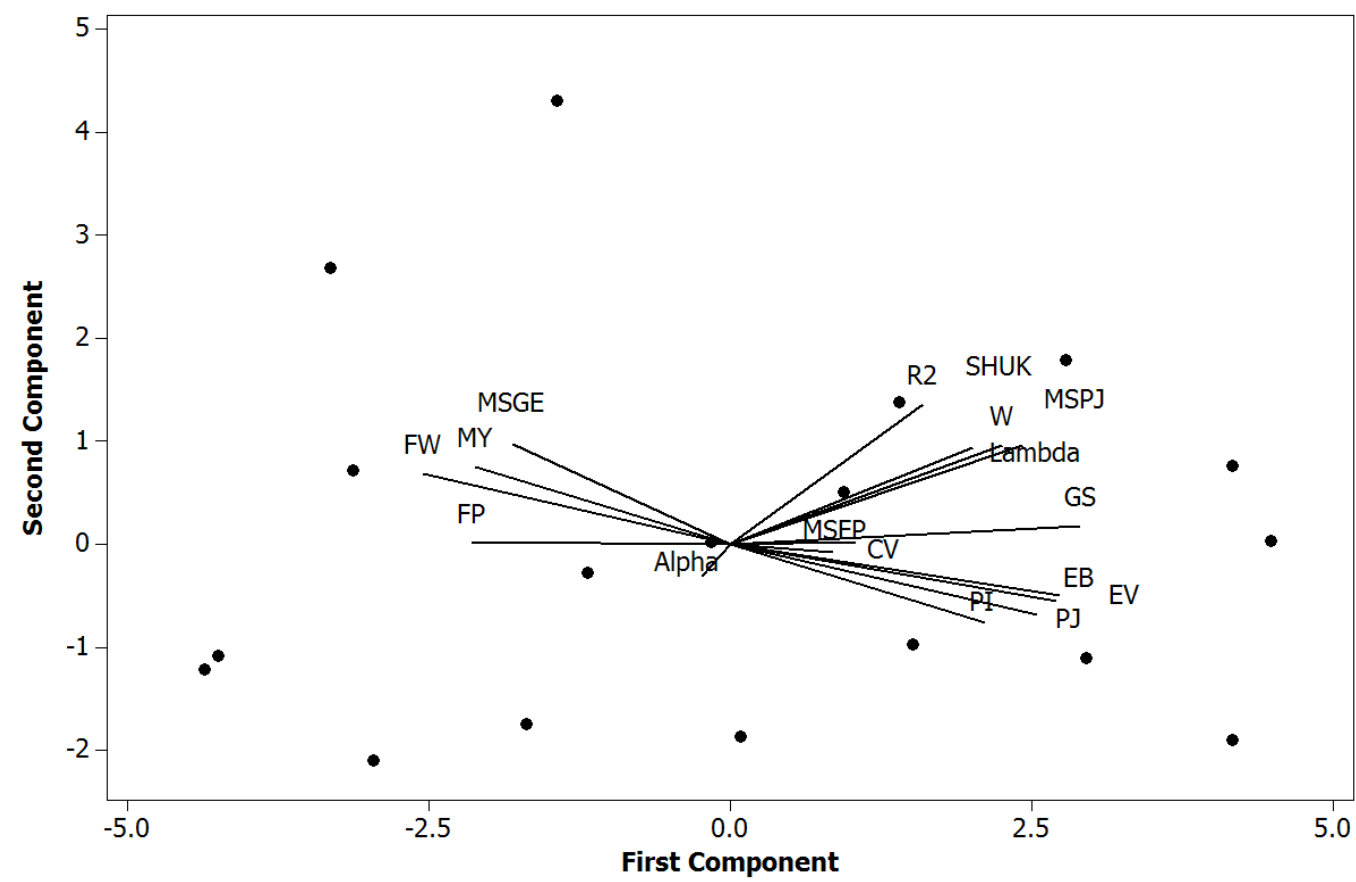

Each of the stability methods produced a unique genotype ranking and to better understand the relationships among these methods, a principal component analysis (PCA) based on the rank correlation matrix was performed. The first two principal components explained $68.77 \%(47.1 \%$ and $21.67 \%$ by PC1 and PC2, respectively) of the variance of the original variables. The relationships among the stability statistics were graphically displayed in a plot of PC1 and PC2 (Table 7). In this 
plot, the PC1 axis mainly distinguishes the methods of FW (coefficient of conventional linear regression of Finlay and Wilkinson [7], FP (Coefficient of independent linear regression of Freeman and Perkins [10]) and MSGE (mean squares of GE of Superiority Index measure of Lin and Binns [20]) from the other methods which mean yield (MY) also is grouped near these statistics, and I refer to these as class 1 (C1) stability statistics versus the other remained stability statistics as Class 2 (C2). It could be concluded that the studied stability statistics are classified into two major groups which reflects dynamic versus static stability concepts. Therefore, it seems that considering high amounts of coefficient of determination of regression model in this investigation, the coefficient of linear regression models were suitable for interpretation GEI.

The following findings can be summarized from the present investigation: (1) genotypes G10 and G18 were found to be the most stable genotypes and (2) the linear regression model and its slope as stability statistics was found to be useful in detecting the phenotypic stability of the studied genotypes when the coefficient of determination are high; and (3)the significant GEIs and the changes in ranks of genotypes across environments suggest a breeding strategy of specially adapted genotypes in homogeneously grouped environments.

\section{AKNOWLEDGements}

This research was part of the national soybean research project of the Ethiopian Institute of Agricultural research (EIAR) of Ethiopia and was supported the Agricultural Revolution in Africa (AGRA-pass 030-2012). I thank all members of the soybean project who contributed to the implementation of the field work.

\section{REFERENCES}

[1] Romagosa, P.N. Fox, Genotype $\times$ environment interaction and adaptation, in: M.D. Hayward, N.O. Bosemark, I. Romagosa (Eds.), Plant Breeding: Principles and Prospects, Chapman \& Hall, London 1993, pp. 373-390.

[2] H.C. Becker, J. Leon, Stability analysis in plant breeding, Plant Breed. 101 (1988) 1-23.

[3] D.E. Byth, R.L. Eisemann, I.H. Delacy, Two-way pattern analysis of a large data set to evaluate genotypic adaptation, Heredity 37 (1976) 215-230.

[4] M. Cooper, I.H. DeLacy, Relationships among analytic methods used to study genotypic variation and genotype-by environment interaction in plant breeding multi environment trials, Theor. Appl. Genet. 88 (1994) 561-572.

[5] I.H. DeLacy, R.J. Redden, D.G. Butler, T. Usher, Analysis of line $\times$ environment interactions for yield in navy beans: 3. Pattern analysis of environments over years, Aust. J. Agric. Res. 51 (2000) 619-628.

[6] R. Shorter, D.E. Byth, V.E. Mungomery, Genotype $\times$ environment interactions and environmental adaptation: II. Assessment of environmental contributions, Aust. J. Agric. Res. 28 (1977) 223-235.

[7] Finlay, K.W., G.N. Wilkinson, 1963. The analysis of adaptation in a plant breeding programme. Aus. J. Agric. Res. 14:742-754.

[8] Eberhart, S.A. and Russell, W.A. 1966. Stability parameters for comparing varieties. Crop Science 6:36-40.

[9] Perkins, J.M., J.L. Jinks, 1968. Environmental and genotype environmental components of variability. Heredity. 23:339-356.

[10] Freeman, G.H., J.M. Perkins, 1971. Environmental and genotype-environmental components of variability VIII. Relations between genotypes grown in different environments and measures of these environments. Heredity. 27:15-23.

[11] Crossa J. Statistical analyses of multilocation trials. Adv. Agron. 1990; 44: 55-85.

[12] Flores, F., Moreno, M.T. and Cubero, J.I. 1998. A comparison of univariate and multivariate methods to analyze GxE nteraction. Field corps research $56: 271-286$.

[13] F.A. van Eeuwijk, J.B. Denis, M.S. Kang, Incorporating additional information on genotypes and environments in models for two-way genotype by environment tables, in: M.S. Kang, H.G. Gauch (Eds.), Genotype-by-Environment Interaction, CRC Press, Boca Raton, FL 1996, pp. 1549. 
[14] C.P. Baril, J.B. Denis, R. Wustrnan, F.A. van Eeuwijk, Analyzing genotype by environment interaction in Dutch potato variety trials using factorial regression, Euphytica 82 (1995) 149155.

[15] Pinthus, J.M., 1973. Estimate of genotype value: a proposed method. Euphytica. 22:121-123.

[16] Rocha, M.M., Vello, N.A., Maia, M.C.C. and mLopes, A.C.A. 2002. Magnitude of Genotype x Environment Interaction for Oil Content Trait in Soybean Lines. Revista Brasileira de Oleaginosase Fibrosa 6:617-625.

[17] R.W. Zobel, M.G. Wright, H.G. Gauch, Statistical analysis of yield trial, Agron. J. 80 (1988) 388-393.

[18] Wricke, G.1962. ber eine methode zur erfassung der ökologischen Streubreite in feldversuchen. Z. Pflanzenzü̈htg. 47: 92-96.

[19] Shukla, G.K. 1972. Some Statistical Aspects of Partitioning Genotype-Environment Components of Variability. Heredity 29: 237-245.

[20] Lin, C.S. and Binns, M.R. 1988. A Superiority Measure of Cultivar Performance for Cultivar x Location Data. Canadian Journal of Plant Science 68: 193-198.

[21] Peterson, C.J., P.S. Graybosch, P.S. Baenziger, A.W. Grombacher, 1992. Genotype and environment effects on quality characteristics of hard red winter wheat. Crop Sci.32:98-103.

[22] Francis, T.R. and L.W. Kannenberg. 1978. Yield Stability Studies in Short-season Maize : A descriptive method for grouping genotypes. Canadian Journal of Plant Science 58 : 1029- 1034.

[23] Hanson, W.D., 1970. Genotypic stability. Theor. Appl. Genet.40:226-231.

[24] Tai GCC. Genotypic stability analysis and its application to potato regional trials. Crop Sci. 1971; 11: 184-190.

[25] Thillainathan M, Fernandez GC. SAS applications for Tai's stability analysis and AMMI model in Genotype x Environmental Interaction (GEI) effects. J. Hered. 2001; 92: 367-371.

[26] Allard, R.W. and Bradshaw, A.D. 1964. Implications of genotype-environmental interactions in applied plant breeding. Crop Science 4: 503-508.

[27] Hussein MA,Bjornstad A, Aastveit AH. SASG x ESTAB: A SAS program for computing genotype x environment stability statistics. Agron. J. 2000; 92: 454-459.

[28] Asfaw A, Alemayehu F, Gurum F, Atnaf M. AMMI and SREG GGE biplot analysis for matching varieties onto soybean production environments in Ethiopia. Scient. Res. Essays,2009; 4: $1322-1330$

[29] P.J. Bramel-Cox, Breeding for reliability of performance across unpredictable environments, in: M.S. Kang, H.H. Gauch Jr. (Eds.), Genotype-by-Environment Interaction, CRC Press, Bota Raton, Florida 1996, pp. 309-339

[30] Rao, M.S., Mullinix, B.G., Rangappa, M., Cebert, E., Bhagsari, A.S., Sapra, V.T.,Joshi, J.M. and Dadson, R.B. 2002. Genotype x Environment Interactions and Yield Stability of Food-Grade Soybean Genotypes. Agronomy Journal 94:72-80.

[31] Adie MM, Krisnawati A, Susanto GWA. Interaksi galur x lingkungan, potensi hasil dan stabilitas hasil galur harapan kedelai hitam [Genotype by environment interaction, yield potential, and stability of black soybean promising lines]. Jurnal Biologi 2013, 12: 79-86. [Bahasa Indonesia].

[32] Bertero, H.D., A.J. de la Vega, G. Correa, S.E. Jacobsen, A. Mujic, 2004. Genotype and genotype-by-environment interaction effects for grain yield and grain size of quinoa (Chenopodium quinoa Willd.) as revealed by pattern analysis of international multi-environment trials. Field Crops Res.89:299-318. 